\title{
A Revised Reversed Carnot Cycle Heat Pump with Close Energy Flow Cycle \& without Temperature Gap: Do We Really Need to Extract Heat from Ambient for Heating
}

Yijun Yuan

University of South China, Hengyang, Hunan, 421001, P.R. China, yuanyijunc@msn.com; yyj@usc.edu.cn

\begin{abstract}
A revised reversed Carnot cycle without external heat source and temperature gap is proposed to challenge the classic reversed Carnot cycle, heat pumps based on the proposed cycle with super energy efficiency works just like electric heater fitted for any climate including extreme cold weather, the application of these new heat pumps is discussed with conclusion that little real obstacles exist for scale application to address the heating related climate change, also a demonstration case shows a remarkable results to encourage the applications of these new heat pumps.
\end{abstract}

Keywords: Revised reversed Carnot Cycle, Reversed Carnot cycle, Heat pump, Heating, Close energy flow, Electric heater.

\section{Introduction}

It is hard to exactly calculate how much energy is used for heating, but the energy cost for heating is tremendous definitely as heating is widely required for everywhere not limited to the building, More than half of energy use in homes is for heating and air conditioning (1), only the residential and service sectors are responsible for over one-third of global final energy usage and around $40 \%$ of total $\mathrm{CO} 2$ emissions According to the International Energy Agency (2). 
Heat pump appears to play an important role in suitable heating, this, in turn, is thought to pave a way toward justification of the application of existing heat pump with open energy flow and temperature gap, most of which extracts heat from ambient. A central challenge for the heat pump, however, is to provide an account of how it works efficiently to satisfy the demand. Energy, Emissions and Equity (E3) Initiative sponsored by US Department of Energy (3) and UK government's Net Zero Innovation Portfolio (NZIP) (4) try to find solutions. The existing heat pump is accompanied with two major issues: the low efficiency especially for cold climate application, frost forming during operation which, in turn leads to low efficiency and also the decrease of the heating capacity. Both originated from low evaporation temperature, which occurs when heat pump extracts heat from low ambient temperature. With lower evaporation temperature, the compression ratio for the compression side of heat pump would be larger without doubt, and, more subtly, the temperature gap for expansion side of the heat pump would be also larger, both larger ratio and gap contribute larger energy cost, more saliently, the larger temperature gap account of much of the loss, for example, with evaporation temperature $-20^{\circ} \mathrm{C}$, and condense temperature $50^{\circ} \mathrm{C}$, the gap accounts for $30 \%$ of loss. To address the above "root cause": low evaporation temperature, the new approach proposed here to lift the evaporation temperature upwards greatly by extracting heat from the indoor instead of ambient, moreover, to bridge the temperature gap by recovering the energy with subcooler, with the subcooler, defrosting of the evaporator if necessary required would become easy and without energy loss. The new way provides a route for the application of the heat pump with high efficiency and behaviour comparable to electric heater.

\section{Thermodynamic cycles}

A Carnot cycle defined to be a reversible cycle was proposed in early $19^{\text {th }}$ century, which automatically represents the maximum possible performance for heat engine, an ideal heat pump or refrigerator was thought of as an ideal heat engine that is operating in a reversed Carnot cycle, which laid the foundation of the major developments of heat 
pumps etc. as an universally applicable device. As the name suggests the heat pump with a reversed Carnot cycle works exactly opposite to the heat engine with a Carnot cycle. A typical heat pump for heating absorbs the heat from ambient, which is at low temperature and releases it to the room to keep it hot. The heat pump is just like a sort of mirror imagine copy of the heat engine, we may think our modern technology and advanced techniques might allow us to rethink the heat pump with much more accuracy than our 19 th century counterpart. In reality, there is a plot hole in the reversed process, at the core of the concept of entropy are such non-reversible process as heat transfer etc. the second law of thermodynamics asserts that all transformations occurring in nature take place in a certain direction, in this context, a reversed ideal heat engine does not necessarily mean an ideal heat pump, then why should heat pump works exactly as a reverse Carnot cycle?

The entropy law entail imparting heat to the ambient from heat engine, but for heat pumps, extracting heat from the ambient is not automatically stipulated, but it is widely accepted for granted, the heat source for heat pumps could be from without or within of the building, namely the heat sink could be also heat source. The only restriction on heat pump pertaining to the entropy law is the necessary work input into the heat pump, which would be transferred into heat eventually. Furthermore, in a sudden twist, the Revised Reverse Carnot Cycle (RRCC) heat pump proposed here would vindicate the oft-dismissed lore that absorbs the heat from within and dump the heat equivalent to the input work to the ambient. 

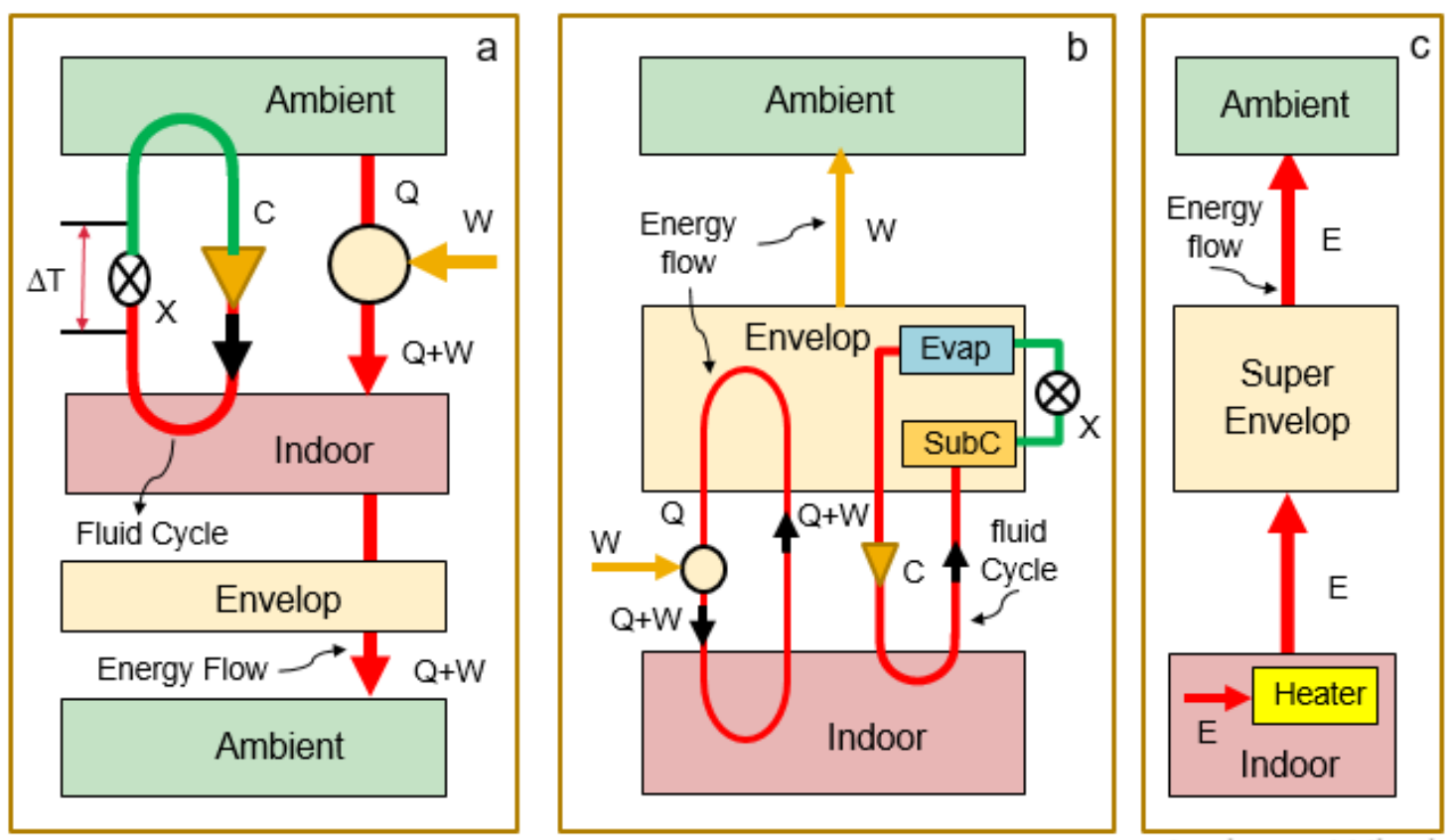

Fig.1 Thermodynamic cycles \& process. a. Reversed Carnot cycle, b. Revised reversed

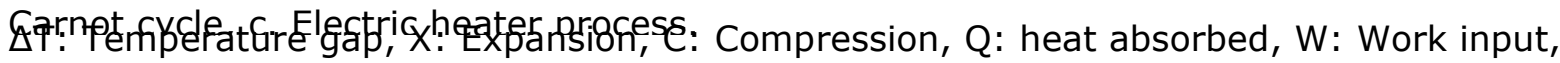
E: Electric input, Evap: Evaporator, Subc: Subcooler.

Fig. 1a shows the classic reversed Carnot cycle, in which, there is an open energy flow, namely, the heat pump with useful work input $\mathrm{W}$ extracts heat $\mathrm{Q}$ from the ambient and expel heat equivalent to $\mathrm{Q}+\mathrm{W}$ into the indoor, at last the envelope liberates the heat equivalent to $\mathrm{Q}+\mathrm{W}$ back into the ambient, the Working fluid cycle with the temperature gap $\Delta \mathrm{T}$ is also shown in Figure 1a,

Fig. 1b shows the revised reversed Carnot cycle, in which, there is a close energy flow, namely, the heat pump with useful work input $\mathrm{W}$ extracts heat $q$ from the envelope which is the dissipated heat from the indoor, and releases heat equivalent to $q+w$ back the indoor, for energy balance, the envelope liberates the heat equivalent to $\mathrm{w}$ into the ambient, the refrigerant cycle without the temperature gap that is bridged with a subcooler, is also shown in Figure $1 \mathrm{~b}$.

The revised reversed Carnot cycle shown in Figure 1a is just like a process with electric heater and super heat shield envelope, which is shown in Fig. 1c. The net heat for indoor is the equivalent amount of electricity of heat pump or the electric heater. But the electric heater 
only generates heat with the electricity, while the heat pump generates heat with the heat shield effect, so electric heater only works with super heat shield envelope, and heat pump works with any normal envelope.

\section{RRCC Heat pump system}

The heat pump system is shown in Fig.2, the heat exchangers connected evaporator and subcooler of the heat pump are embedded into the envelop (a) or installed on the outside (b) or inside (c) of envelop, the subcooler decreases the heat dissipated from indoor and the evaporator absorbs the dissipated heat from indoor. The fluids cycle between the heat exchanger and evaporator or subcooler, the cycle fluid could be liquid or water, Fig. 2 shown is liquid driven by pump. The evaporator or subcooler of the heat pump could be directly embedded into envelop or installed either sides of envelop. The data are also shown in Fig.2, with these data and an APP provide by Bitzer (5), the coefficient of the performance (COP) of the heat pump is 4.46, while the COP only 2.29 for normal heat pump that works at the same conditions assumed the same condense temperature $50^{\circ} \mathrm{C}$ but much lower evaporation temperature $-20{ }^{\circ} \mathrm{C}$, the COP for the heat pump indicated in Fig. 2 is almost double against the normal heat pump.

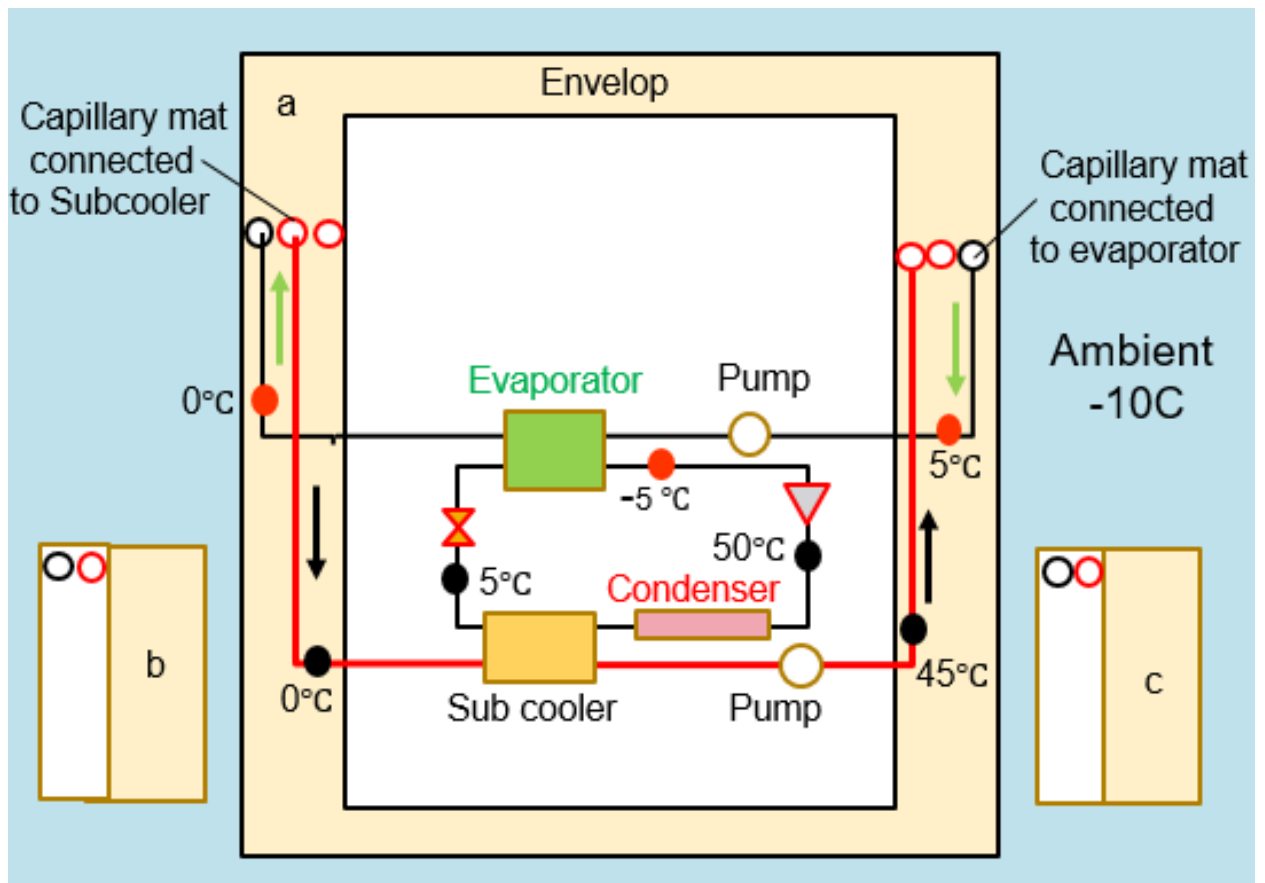

Fig.2 RRCC heat pump system. a. Embedded, b. Outside, c. Inside 


\section{4, Application}

The application of RRCC heat pump require to set up connection between the heat pump and envelop, there are many practice for the so called connections, the pipe-embedded wall is already used for cooling and heating $(6,7)$, and capillary tube mat emerged in 1981(8) is another way with extensive application $(9,10,11)$, even for window, water flow window $(12,13)$ has been explored. Based on this, there is no real obstacle for application of the RRCC heat pumps.

The SolarWall (14) developed in 1989 is also fit for this purpose. Interestingly, Cavity wall construction was introduced in the United Kingdom (15) during the 19th century and gained widespread use in the 1920s, which provide a niche application.

\section{Cavity wall application.}

Masonry cavity construction, which consists of two layers of brick or concrete block separated by a pocket of air. Such buildings are notoriously bad at holding heat $(16,17)$, the majority of buildings in England - and in many already urbanized parts of the globe - were built before modern standards for energy-efficient construction were in place (18), so, with RRCC heat pump, this kind of building in UK could be transferred into super energy efficient building to save energy and decrease greenhouse gas emission.

\section{Apartment Application}

Almost all Chinese urban residential building is apartment type, and some of them installed with underfloor heating system with embedded water pipe, with the same technique, wall embedded pipe system could be applied and RRCC heat pump could be easily applied, which could be replaced existing heating system relying on mainly coal boiler. 


\section{Vehicle application.}

Another niche application is for vehicle, especially for electric vehicle, the heat loss of the envelop of the vehicle is relatively large because of the poor insulation and wind driven convection, the heating for electric vehicle takes large part of the battery capacity, RRCC heat pump address the poor insulation and convection effect to save battery capacity.

\section{Dry Chamber case}

There are six identical chambers for mechanical parts drying with floor area $13.2 \mathrm{~m} 2$, height $5 \mathrm{~m}$, and temperature $60 \mathrm{C}, \mathrm{RH} 10 \%$, electric resistant heater is used for the drying purpose. The drying chamber is located in a factory located in Leshan city, Sichuan province, Southwest of China.

As shown in Fig.3, One of drying chamber is chosen for application the RRCC heat pump to replace electric heater, the annual electric cost for the RRCC is only $15 \%$ of the average electric cost of other fives.

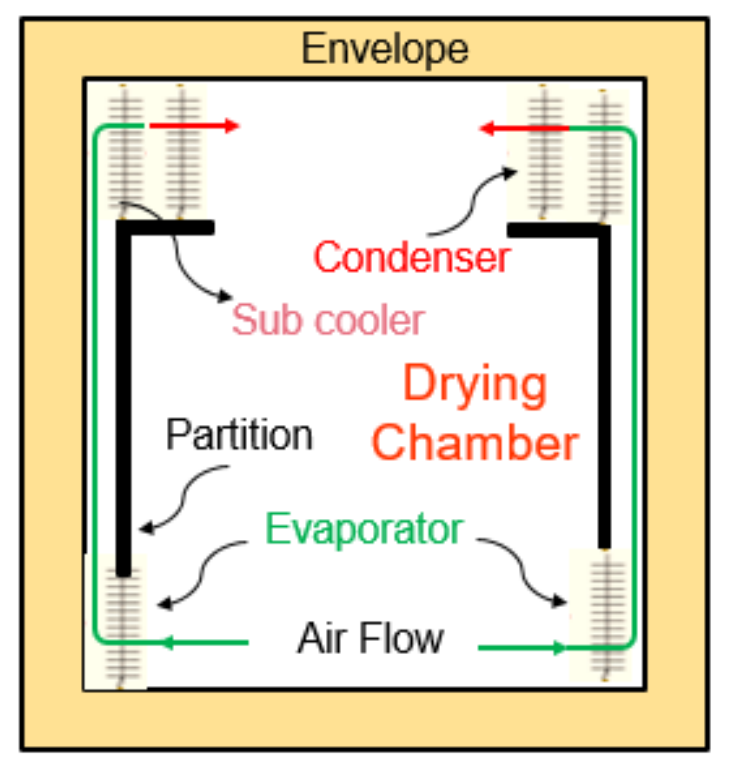

Fig.3 Drying chamber with RRCC heat pump. 


\section{Conclusion}

A revised reversed Carnot cycle with close energy flow and without temperature gap is proposed here to challenge the classic reversed Carnot cycle.

The RRCC heat pump with super energy efficiency and without any external heat source works like electric heater to fit any climate especially for extremely cold weather.

The initial demonstration of RRCC heat pump achieve remarkable energy saving.

The RRCC heat pump is readily for applications to help addressing the climate change, there is no real obstacles for its application.

The RRCC heat pump could be widely used various area for heating including building and vehicle, industry and residential etc.

The Revised Carnot cycle could be also used for cooling, refrigeration, especially for cold storage application.

\section{Reference}

1. https://www.eia.gov/energyexplained/use-of-energy/homes.php

2. IEA,Tracking Buildings 2020, IEA, Paris (2020)

https://www.iea.org/reports/tracking-buildings-2020

3.https://www.gov.uk/government/publications/heat-pump-readyprogramme/information-about-the-heat-pump-readyprogramme?elqTrackId=95D0D60DB2FD80FA06EAD59E9F42405

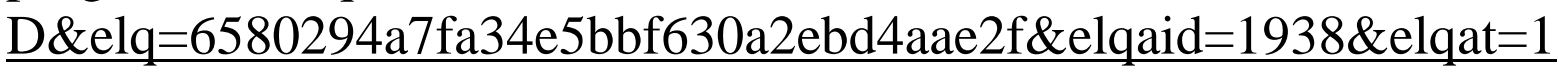
\&elqCampaignId $=$

4. https://www.energy.gov/eere/buildings/energy-emissions-andequity-e3-initiative

5. https://www.bitzer.de/websoftware/ 


\section{M. Krzaczek, J. Florczuk, J. Tejchman}

Improved energy management technique in pipe-embedded wall heating/cooling system in residential buildings, Applied Energy, 254 (2019), p. 113711, 10.1016/j.apenergy.2019.113711

7. Liqun Zhou Chao jie Li, Study on thermal and energy-saving performances of pipe-embedded wall utilizing low-grade energy

https://doi.org/10.1016/j.applthermaleng.2020.115477

8. https://en.wikipedia.org/wiki/Capillary tube mat

9. Nan Li, Qiong Chen, Study on dynamic thermal performance and optimization of hybrid systems with capillary mat cooling and displacement ventilation, Int. J. Refrig., 110 (2020), pp. 196-207

10. F. Zhang, H.A. Guo, Z. Liu, G. Zhang

A critical review of the research about radiant cooling systems in China, Energy Build., 235 (2021), 10.1016/j.enbuild.2021.110756

11.T. Mikeska, S. Svendsen, Study of thermal performance of capillary micro tubes integrated into the building sandwich element made of high performance concrete, Applied Thermal Engineering, 52 (2013), pp. 576-584

12. T.T. Chow, C. Li, Z. Lin, The function of solar absorbing window as a water-heating device, Build. Environ., 46 (2011), pp. 955-960, https://doi.org/10.1016/j.buildenv.2010.10.027

13. T.T.Chow, Yuan liLyu, Effect of design configurations on water flow window performance, Solar Energy, Vol. 155, 10.2017, p. 354362. , https://doi.org/10.1016/j.solener.2017.06.050

14. Transpired Collectors (Solar Preheaters for Outdoor Ventilation Air). Federal Energy Management Program, U.S. Department of Energy. Federal Technology Alert \#DOE/GO-10098-528. April 1998. 15. https://historicengland.org.uk/images-books/publications/eehbearly-cavity-walls/heag083-early-cavity-walls/ 
16. P. Baker, U-values and Traditional Buildings. In Situ Measurements and Their Comparisons to Calculated Values: Historic Scotland, 2011.

17. SAP, Consultation Paper: CONSP: 16: Review of Default UValues for Existing Buildings in SAP, SAP Supporting Document, Building Research Establishment Ltd, 2016.

18. DECC, Statistical release: experimental statistics: estimates of home insulation levels in Great Britain: April 2013, in: DECC (Ed.), London: Department of Energy \& Climate Change, 2013. 